\title{
THE SYNTHESIS OF A WATER-SOLUBLE DERIVATIVE OF RUTIN AS AN ANTIRADICAL AGENT
}

Carla Aparecida Pedriali* and Adjaci Uchoa Fernandes

Departamento de Bioquímica, Instituto de Química, Universidade de São Paulo, Av. Prof. Lineu Prestes, 748, 05508-900 São Paulo - SP, Brasil

Leandra de Cássia Bernusso and Bronislaw Polakiewicz

Departamento de Tecnologia Bioquímico-Farmacêutica, Faculdade de Ciências Farmacêuticas, Universidade de São Paulo, Av. Prof. Lineu Prestes, 580, 05508-900 São Paulo - SP, Brasil

Recebido em 13/6/07; aceito em 20/6/08; publicado na web em 31/10/08

\begin{abstract}
The purpose of this study was to synthesize a water-soluble derivative of rutin (compound 2) by introducing carboxylate groups on rutin's sugar moiety. The rutin derivative showed an almost 100-fold solubility increase in water. The antiradical capacity of compound 2 was evaluated using the luminol/AAPH system, and the derivative's activity was 1.5 times greater than that of Trolox ${ }^{\circledR}$. Despite the derivative's high solubility in water $(\log P=-1.13)$, lipid peroxidation of brain homogenate membranes was very efficiently inhibited (inhibition values were only $19 \%$ lower than the inhibition values of rutin).
\end{abstract}

Keywords: water-soluble derivative of rutin; antiradical capacity; antioxidant activity.

\section{INTRODUCTION}

The study of free radicals and antioxidant mechanisms with respect to cellular oxidative stress grew in importance following McCord's and Fridovich's studies about superoxide dismutase (SOD). ${ }^{1}$ Flavonoids are exogenous antioxidants and perform in different stages of the oxidative processes, including acting as radical scavengers, hydrogen donors, electron donors, peroxide decomposers, singlet oxygen quenchers, enzyme inhibitors, and synergist and metal-chelating agents. ${ }^{2-6}$ The biological activities of flavonoids were first suggested by Rusznyàk and Szent-Gÿorgyi, ${ }^{7}$ who reported that citrus-peel flavonoids were effective in the prevention of capillary bleeding and fragility brought on by scurvy. Additionally, this group of compounds is currently being extensively researched because of its wide range of pharmacological properties, including antioxidative, anti-allergic, anti-inflammatory, anti-diabetic, hepato- and gastro-protective, antiviral, and anti-neoplastic properties. ${ }^{8-11}$

Rutin (3-[[6-O-(6-Deoxy- $\alpha$-L-mannopyranosyl)- $\beta$-D-glucopyranosyl]oxy]-2-(3,4-dihydroxyphenyl)-5,7-di hydroxyl-4H-1-benzopyran-4-one) (1) is a bioactive plant flavonoid that is of great importance as a potentially useful therapeutic drug to inhibit free-radical, mediated cytotoxicity and lipid peroxidation. ${ }^{12}$ In addition, rutin improves the resistance and permeability of capillary vessels..$^{13,14}$

The use of rutin is relatively limited due to its low water solubility $(0.125 \mathrm{~g} / \mathrm{L}),{ }^{15}$ which is what led to our research group's desire to increase the solubility of a rutin derivative (as synthesized by introducing carboxylate groups on rutin's sugar moiety, by means of a modification of the method developed by Alluis et al. $).{ }^{16}$ Moreover, we took into consideration the influence of the chemical modification via evaluation in vitro of two model procedures: antiradical capacity by luminol/AAPH system and antioxidant activity by lipid peroxidation in brain homogenate.

\section{EXPERIMENTAL}

\section{Instrumentation}

A Shimadzu TCC-240A spectrophotometer was used to mea-

*e-mail: capedriali@hotmail.com sure the UV-Vis spectra. The NMR spectra were obtained using a Bruker ADVANCE DRX-500 instrument operating at $500.13 \mathrm{MHz}$. ${ }^{1} \mathrm{H}$-signals were assigned from $1 \mathrm{D}$ - and $2 \mathrm{D}$-COSY experiments. ${ }^{13} \mathrm{C}$ signals were assigned from 1D- and 2D-COSY and HETERO-COSY experiments. The antiradical assay was performed on an EG\&G Berthold LB96V microplate luminometer at $37^{\circ} \mathrm{C}$.

\section{Reagents and materials}

Rutin (98.8\%) was purchased from Natural Pharma, Brazil. 2-Thiobarbituric acid (TBA), trichloroacetic acid (TCA), $\alpha$-tocopherol, (hydroxymethyl)aminomethane (TRIS), succinic anhydride were obtained from Sigma Chemical, USA. Sodium chloride, monobasic sodium phosphate, monohydrate $\left(\mathrm{NaH}_{2} \mathrm{PO}_{4} \cdot \mathrm{H}_{2} \mathrm{O}\right)$, dibasic sodium phosphate $\left(\mathrm{Na}_{2} \mathrm{HPO}_{4}\right)$, pyridine and buthanol were purchased from Merck, USA. 2,2'- Diazobis (2-amidino-propane) dihydrochloride (AAPH), 5-amino-2,3-dihydro-phthalazine-1,4-dione (luminol) and 6-hydroxy-2,5,7,8-tetramethylchroman-2-carboxilic acid $\left(\right.$ Trolox $\left.{ }^{\circledR}\right)$ were obtained from Aldrich Chemical, USA. All other chemicals were reagent grade.

\section{Animals \\ Adult male albino Wistar rats (150-200 g) from the laboratory at the Faculty of Pharmaceutical Science, University of São Paulo, were used in this study. The rats were housed under normal laboratory conditions ( $22 \pm 2{ }^{\circ} \mathrm{C}, 12 / 12$-h light-dark cycle) with free access to standard rodent chow and water. \\ Synthesis of 2-(3,4-dihydroxyphenyl)-5,7-dihydroxy-3- $\{\{2,3,4-$ tris-O-(3-carboxy-1-oxopropyl)-6-O-[2,3,4-tris-O-(3- carboxy-1-oxopropyl)-6-deoxy- $\alpha-L-m a n n o p y r a n o s y l]-\beta-D-$ glucopyranosyl\}oxy\}-4H-1-benzopyran -4-one (2)}

A solution of rutin (1) ( $5 \mathrm{~g}, 8.2 \mathrm{mmol})$ and succinic anhydride (7.5 g, $74.94 \mathrm{mmol})$ in pyridine $(200 \mathrm{~mL})$ was stirred at $70{ }^{\circ} \mathrm{C}$ for $24 \mathrm{~h}$. The solvent was removed under vacuum and the residue was dissolved in warmed buthanol $(20 \mathrm{~mL})$ and filtered with cooled ether $(20 \mathrm{~mL})$. 
The crude product was solubilized in methanol, and its separation was achieved through preparative paper chromatography (Whatman $3 \mathrm{MM}, 46 \mathrm{X} 57 \mathrm{~cm}$, Maldstone, UK) with AcOEt/acetone/ $\mathrm{HCO}_{2} \mathrm{H} /$ $\mathrm{H}_{2} \mathrm{O}(20: 2: 1: 1) .{ }^{17}$ The eluate was concentrated as a yellow powder under reduced pressure at $40^{\circ} \mathrm{C}$. Scheme 1 shows the synthesis of compound 2. ${ }^{16}$ UV/VIS (water): 352, 271. TLC (silica gel $60 \mathrm{~F}_{254}$ TLC plates, AcOEt/acetone/ $\mathrm{HCO}_{2} \mathrm{H}_{/} \mathrm{H}_{2} \mathrm{O}$ 20:2:1:1): $\mathrm{R}_{\mathrm{f}}$ 0.5. Molar Absorption Coefficient $-\varepsilon_{\max } \mathrm{M}^{-1} \mathrm{~cm}^{-1}$ (TRIS-HCl buffer - $\mathrm{pH} 7.4$ ): 3,523 (352 nm) and (1-octanol): $257(365 \mathrm{~nm}) .{ }^{1} \mathrm{H}-\mathrm{NMR}\left(\left(\mathrm{D}_{6}\right) \mathrm{DMSO}\right.$, $500 \mathrm{MHz}): 12.69$ (1s, OH-C(5)); $7.66\left(\mathrm{~m}, 1 \mathrm{H}, \mathrm{H}-\mathrm{C}\left(2^{\prime}\right)\right)$; 7.51-7.57 $\left(\mathrm{m}, 1 \mathrm{H}, \mathrm{H}-\mathrm{C}\left(6^{\prime}\right)\right) ; 6.83$ (d, J=8.0, 1H, H-C (5')); 6.41 (d, J=2.0, 1H, $\mathrm{H}-\mathrm{C}(8)) ; 6.19$ (d, J=2.5, 1H, H-C(6)); 5.50 (d, J=7.0, 1H, H-C(1'^)); $5.36\left(\mathrm{t}, \mathrm{J}=7.5,1 \mathrm{H}, \mathrm{H}-\mathrm{C}\left(3^{\prime \prime}\right)\right) ; 5.29\left(\mathrm{t}, \mathrm{J}=8.0,1 \mathrm{H}, \mathrm{H}-\mathrm{C}\left(2^{\prime \prime}\right)\right) ; 4.84(\mathrm{t}$, $\left.\mathrm{J}=9.75,1 \mathrm{H}, \mathrm{H}-\mathrm{C}\left(4^{\prime \prime}\right)\right) ; 4.63$ (t, J=9.67, 1H, H-C(4"')); 4.43 (s, 1H,

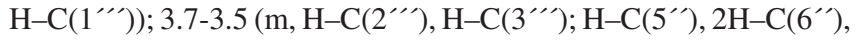
$\left.\mathrm{H}-\mathrm{C}\left(5^{\prime \prime \prime}\right)\right) ; 2.40$ (s, 24H, 6( $\left.\mathrm{CH}_{2} \mathrm{CH}_{2} \mathrm{COOH}\right)$ ); 0.97 (d, J=6.0, 3H, $\left.\mathrm{Me}\left(6^{\prime \prime \prime}\right)\right) .{ }^{13} \mathrm{C}-\mathrm{NMR}\left(\left(\mathrm{D}_{6}\right) \mathrm{DMSO}, 500 \mathrm{MHz}\right): 177.7$ (C(4)); 174.7$174.0\left(\mathrm{CO}_{2} \mathrm{H}\right) ; 172.5-172.2\left(\mathrm{COCH}_{2} \mathrm{CH}_{2} \mathrm{COOH}\right) ; 164.8(\mathrm{C}(7))$; 161.6 (C(5)); 157.0 (C(8a)); $156.9(\mathrm{C}(2)) ; 149.0$ (C(4')); 145.4 $\left(\mathrm{C}\left(3^{\prime}\right)\right) ; 133.7(\mathrm{C}(3)) ; 121.9\left(\mathrm{C}\left(6^{\prime}\right)\right) ; 121.5\left(\mathrm{C}\left(1^{\prime}\right)\right) ; 116.7\left(\mathrm{C}\left(2^{\prime}\right)\right)$;

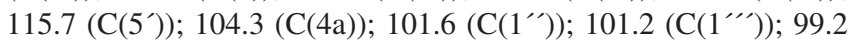
$(\mathrm{C}(6)) ; 94.1(\mathrm{C}(8)) ; 74.5\left(\mathrm{C}\left(3^{\prime \prime}\right)\right) ; 72.3\left(\mathrm{C}\left(5^{\prime \prime}\right)\right) ; 72.2\left(\mathrm{C}\left(2^{\prime \prime}\right)\right) ; 72.1$

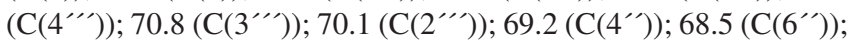
$67.4\left(\mathrm{C}\left(5^{\prime \prime \prime}\right)\right) ; 29.4-29.1\left(\mathrm{CH}_{2} \mathrm{CH}_{2} \mathrm{COOH}\right) ; 18.1$ (Me(6"')).

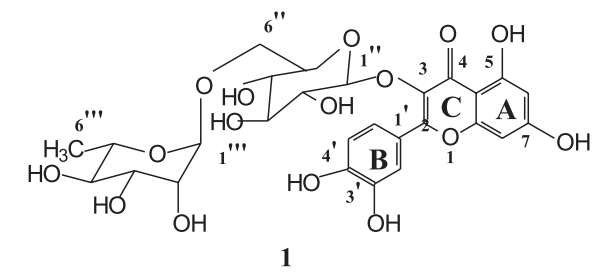

(i)
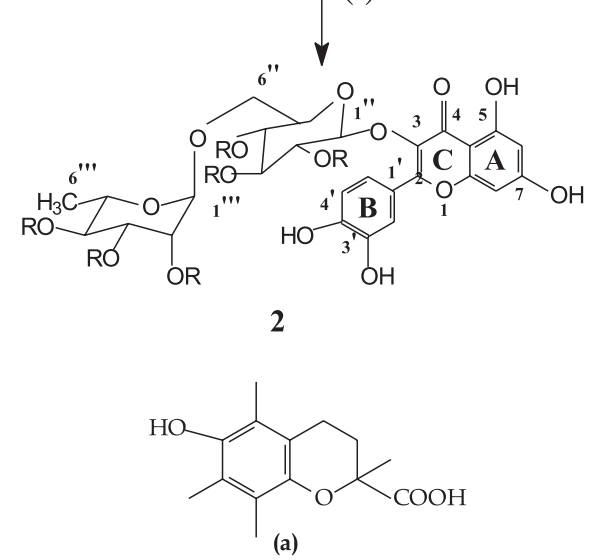

Scheme 1. Synthesis of rutin derivative 2. (i) Pyridine, succinic anhydride, $70{ }^{\circ} \mathrm{C}, 24 \mathrm{~h}, 2 \mathrm{R}=\mathrm{C}(=\mathrm{O}) \mathrm{CH}_{2} \mathrm{CH}_{2} \mathrm{COOH}$ (a) Comparison of chemical structure of Trolox ${ }^{\circledR}$ (6-hydroxy-2,5,7,8-tetramethyl chroman-2-carboxilic acid) with rutin

\section{Determination of solubility and evaluation of the experimental} octanol-water partition coefficient $(\log P)$

Flavonoid glycosides are natural compounds that are soluble in water and alcohols. A fair number are sparingly soluble, such as rutin and hesperidin. The assay was carried out in petri-plates at $25^{\circ} \mathrm{C}$; the rutin and derivative 2 weighed $3 \mathrm{mg}$; and $300 \mu \mathrm{L}$ of the following solvents were added: hexane, acetate ethyl, $N$ - $N$-dimethylformamide, pyridine, chloroform, water, ether, ethyl alcohol absolute, methanol, toluene, glycerin and acetonitrile. ${ }^{15}$

The methodology to evaluate the octanol-water partition coefficient was a modification of the methodology elaborated by Rothwell et $a l .{ }^{18}$ The rutin and derivative $\mathbf{2}$ were dissolved in a system of 1-octanol ( $3 \mathrm{~mL}$ ) and TRIS-HCl buffer ( $3 \mathrm{~mL}, \mathrm{pH} 7.4)$ and were agitated for 30 minutes. Subsequently, the phases were centrifuged for 9 minutes at $2000 \mathrm{~g}$. Both fractions were analyzed using a UV spectroscopy. The $\log P$ value was calculated as $\log$ [ratio of the concentration in the octanol phase to the concentration in the aqueous phase at $\mathrm{pH} 7.4]$.

\section{Determination of antiradical capacity using AAPH-luminol induced chemiluminescence $(\mathrm{CL})$ measurements}

Krasowska et al. ${ }^{19}$ established the conditions of CL intensity in the luminol-AAPH system and the most appropriate results of light intensity, such being linear growth at a $\mathrm{pH}$ range of 7.0 to 10.5 and a temperature of $30-37^{\circ} \mathrm{C}$. In our study, the luminescence generation, at $\mathrm{pH}$ 9.0, was strong and long-lasting with reproducible results around 25,000-30,000 RLU (relative light units), which was 5001,000 times higher than the background level (empty plate about 30 RLU/s, luminol alone $50 \mathrm{RLU} / \mathrm{s}$ ). Based on this data, we decided to conduct our experiments with the luminol-AAPH system at $37^{\circ} \mathrm{C}$ in $0.1 \mathrm{M}$ Tris $\mathrm{pH} 9.0$ buffer, using a freshly stocked solution of AAPH in neutral water, with a final volume of $250 \mu \mathrm{L}$ on white microplates. The chemiluminescent reaction was initiated and, 11 minutes later, the antiradical sample solutions were added.

Trolox $^{\circledR}$ has been used as a reference compound because it is a pure and cell-permeable substance with known physicochemical properties and because it is a water-soluble derivative of vitamin $\mathrm{E}$ with potent antioxidant properties, such as the prevention of peroxynitrite-mediated oxidative stress and of apoptosis in rat thymocytes. Also, it is stable for many hours in a solution at room temperature, and its addition to the luminol system results in almost complete suppression of light emission, which is restored immediately after total consumption. ${ }^{20-22}$

\section{Quantification}

In this method, the intensity of light emission varies with time. The area under the chemiluminescence decay curve of the standard reaction represents the total amount of reactive species present in the reaction media, which generate light emission. ${ }^{23,24}$ Antiradical compounds scavenge these reactive species and thereby suppress light emission. The difference between the graph areas in the presence and absence of an antiradical compound represents the number of reactive species consumed by the antiradicals, with the value being proportional to the concentration of antiradicals added to the system and a measure of its antiradical capacity. ${ }^{24}$ The plot of the antiradical concentration vis-à-vis the suppression area is theoretically expected to yield a straight line (Figure 1), and the antiradical capacity of the sample compound is determined by comparing the slope obtained with a sample compound $\left(\alpha_{s}\right)$ and the slope obtained with Trolox ${ }^{\circledR}\left(\alpha_{T}\right)$. As Trolox ${ }^{\circledR}$ is capable of scavenging two radicals per molecule, the number of radicals trapped by one sample molecule $\left(n_{s}\right)$ is obtained using Equation 1.23-26

$n_{s}=\frac{\alpha_{s}}{\alpha_{T}} \times 2$

Determination of antioxidant activity using a model procedure for studying lipid peroxidation in the biological system in vitro

The in vitro antioxidant activity of rutin and its derivative was evaluated according to the method proposed by Stocks et al.. ${ }^{27}$ This 
method is based on the inhibition of spontaneous lipid peroxidation of brain homogenates when incubated at controlled temperature and oxygenation conditions. For the in vitro studies, the rats were sacrificed using ether anesthesia. The brains were perfused, through the superior vena cava, with ice-cold $140 \mathrm{mM} \mathrm{NaCl}, 40 \mathrm{mM}$ sodium phosphate buffer solution $\mathrm{pH} 7.4$, which were then removed and homogenized with the same buffer $(1: 4 \mathrm{w} / \mathrm{v})$. The absorbance of the MDA-TCA (malondyaldehyde-trichloroacetic acid) adduct was detected at $535 \mathrm{~nm}$.

The antioxidant activity of samples was expressed in terms of percentage of inhibition of spontaneous autoxidation (as measured in the control homogenate). The antioxidant activity (\% inhibition) was calculated using the following formula:

Antioxidant activity $(\%$ inhibition $)=1-\frac{A 1(\text { hour })-A 1(\text { zero }- \text { time })}{A(\text { hour })-A(\text { zero-time })} \times 100$

whereby $A \mathrm{l}=$ absorbance of the test sample and $A=$ the absorbance of the control.

\section{Statistical data}

All values are expressed as mean \pm standard deviation $(\mathrm{SD})$ of at least three independent experiments. The data has been statistically analyzed using one-way analysis of variance. The level of statistical significance is taken at $P<0.05$. All calculations have been performed using Microcal Origin 6.0 (1999).

\section{RESULTS AND DISCUSSION}

\section{Determination of synthesis and solubility}

The chemical synthesis of water-soluble derivatives of rutin, as reported by Alluis et al, ${ }^{16}$ is based on the introduction of sulfate and carboxylate groups on the sugar moiety of rutin, with the aim being to increase rutin's water solubility. There were condition variations in the Alluis study, including: solvent (pyridine and DMF) and temperature (range $0-70^{\circ} \mathrm{C}$ ) variations, catalyst (4-dimethylaminopyridineDMAP) and succinic-anhydride or $\mathrm{SO}_{3}$ variations, and pyridine-concentration variations (an excess of 3 at 6 moles with respect to rutin). In our experiment, compound $\mathbf{2}$ was prepared by making a simple modification to Alluis' experiment, specifically reacting the rutin with succinic anhydride in excess of 6 moles at a temperature of $70{ }^{\circ} \mathrm{C}$ for $24 \mathrm{~h}$ in pyridine, not using a catalyst for acylation reactions. In addition, this compound was separated and isolated, and we followed the standardized procedures of preparative paper chromatography, as mentioned by Siegelman and as opposed to the chromatography on $C_{18}$ silica gel implemented by Alluis et al.. ${ }^{16}$

In this current experiment, the NMR technique $\left({ }^{13} \mathrm{C}-\mathrm{NMR}\right.$ and ${ }^{1} \mathrm{H}-$ NMR spectra) was used to identify the structure of compound $\mathbf{2}$ and to confirm the efficacy of separation using the paper-chromatography method. Analysis was conducted by means of analytical data (according to the experimental description of derivative 2). Indeed, the quantitative assignment of all signals confirms the purity of the sample. Integration of the peak assignments in the ${ }^{1} \mathrm{H}$-NMR spectrum sustained and correlated to the quantitative yield of rutin 2", $3^{\prime \prime}, 44^{\prime \prime}, 2^{\prime \prime \prime}, 3^{\prime \prime \prime}, 44^{\prime \prime \prime}$-hexakis (hydrogen succinate) and any modification in the hydroxyls of flavonoid nucleus. This process was implemented using the MestreNova program, version 5.0.1-1979, 2007 of Mestre Lab Research S.L.

One of the methods used to determine the compound's solubility was the octanol-water partition coefficient $(\log \mathrm{P})$ value. This value is a parameter that relates single-solute partitions between polar (water) and nonpolar (octanol) phases, which determines in vitro solubility in appropriate pharmaceutical and cosmetic preparations. ${ }^{18}$
The water solubility of derivative $2(10 \mathrm{~g} / \mathrm{L})$ showed an almost 80 -fold increase over that of rutin $(0.125 \mathrm{~g} / \mathrm{L})$. This occurred as a result of the mixture of compounds with variable amounts of succinic anhydrides introduced on sugar moiety, which showed short alkyl chain lengths and strong interaction of carboxylate groups with water. Thus, derivative $\mathbf{2}$ became insoluble in apolar solvents, which have a low dielectric constant (Table 1). This solubility result was also confirmed by the octanol-water partition coefficient data (Table 1), because derivative 2 had a higher $\log P(-1.13 \pm 0.02)$ than that of rutin $\log P(0.85 \pm 0.05)$. Therefore, the method used to chemically modify rutin proved to be satisfactorily efficient and practical with regard to our stated purpose.

Table 1. Solubility of rutin and its derivative $\mathbf{2}$ in some common solvents. Experimentally determined $\log P$ values in an octanol/ water system

\begin{tabular}{lcc}
\hline Solvents & Rutin & 2 \\
\hline Protic solvents & & + \\
Water & \pm & \pm \\
Methanol & + & \pm \\
Ethilic alcohol $(99,9 \%)$ & & \\
Aprotic Solvents & + & \pm \\
Glycerin & - & + \\
Acetonitrile & + & + \\
$N, N$-Dimethylformamide & + & \pm \\
Pyridine & + & - \\
Ethyl acetate & \pm & - \\
Chloroform & \pm & - \\
Diethyl ether & \pm & - \\
Tholuen & \pm & $-1.13 \pm 0.03$ \\
Hexane & $0.85 \pm 0.07$ & \\
log $P \pm$ SD $(\mathrm{n}=3)$ & & \pm
\end{tabular}

$(+)$ soluble, $( \pm)$ partially soluble, $(-)$ insoluble

\section{Determining antiradical and antioxidant capacities}

Two different methodologies were used to quantify the inhibition, by compound $\mathbf{2}$, of water-soluble and liposoluble generated free radicals; this was deemed necessary because of the great interest generated by the derivative's high solubility in water and to demonstrate, pursuant to the FDA (Food and Drug Administration), ${ }^{28}$ the low citotoxicity of succinic anhydride when used in oral preparations.

One of the assays was based on chemiluminescence measurements and was discussed previously by Lissi et al..$^{25}$ These measures were proposed to determine the TRAP (total radical-trapping antioxidant parameter) value, which is an index that corresponds to the ratio of the number of radicals trapped per molecule of additive (pure compound) to the number trapped per Trolox ${ }^{\circledR}$ molecule. Therefore, this method is both simple and sensible..$^{19,25,29}$ It uses luminol as the light source, a compound that emits intense chemiluminescence when oxidized by different kinds of free radicals in the presence of oxygen or other oxidants, ${ }^{30}$ such as hypochlorous acid and peroxynitrous acid. Lissi et al..$^{23,25}$ have studied the mechanism of luminol chemiluminescence induced by AAPH-derived radicals. This mechanism is driven by the production of chemiluminescent luminol-derived intermediates generated by the reaction of luminol with alkyl peroxyl radicals. Hydrophilic alkyl peroxyl radicals are formed in biological systems from alkyl radicals (produced by AAPH thermolysis) that react at diffusion controlled rates with 


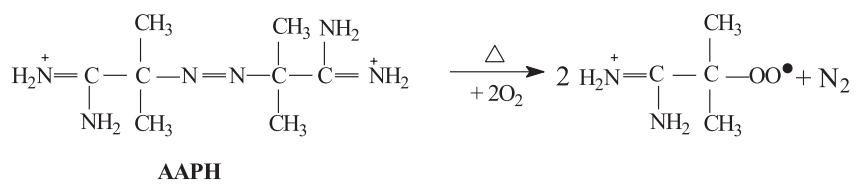

Scheme 2. AAPH (2,2'-azobis-(2-amidinopropane) dihydrochloride) undergoes thermolysis, generating nitrogen and 2 alkyl radicals, which react with oxygen-forming peroxyl radicals

dissolved oxygen (Scheme 2).

Data in Figure 1 shows a linear relationship among the suppression areas, with the antiradical concentrations ranging from 0.2 to 1.0 $\mu \mathrm{M}$ for all compounds studied. The area (RLU) is the region under the chemiluminescence decay curve and represents the suppression of light emission by concentration variation of antiradical compounds. The Trolox ${ }^{\circledR}$ chemical structure in Scheme 1(a) indicates a similarity between Trolox ${ }^{\circledR}$ chromanol nucleus and rutin's flavonoid nucleus, showing that it was most appropriate as a reference compound for the experimental conditions of this method given its solubility and antiradical activity. A comparison of the slopes presented in Figure 1 and the TRAP values in Table 2 shows that the antiradical capacity of compound $2(n=3.03 \pm 0.08)$ is nearly 1.5 times higher than that of Trolox ${ }^{\circledR}(n=2)$ and 0.86 times lower than that of rutin $(n=3.53$ \pm 0.07 ). These results demonstrate that each molecule of derivative 2 and/or rutin can trap around 3 radicals using the luminol/AAPH TRAP assay. At pH 9, compound $\mathbf{2}$ and rutin are more negatively charged because they have four -OH groups with pKa's ranging from 7.1 to $11.65,{ }^{31}$ and six carboxilic groups that are probably all deprotonated. Since we know that AAPH produces positively charged radicals under thermolysis, it becomes clear that the more negatively charged the antioxidant, the better it is for scavenging cationic free radicals. Moreover, preliminary results have shown that succinic anhydride as a sugar substitute ${ }^{32}$ doesn't influence the antiradical activity of compound $\mathbf{2}$. This modification and the study of quantitative structure-activity relationship (QSAR) of this compound will be analyzed in a future study.

The other method used to determine antioxidant activity was the use of a model procedure designed to study lipid peroxidation

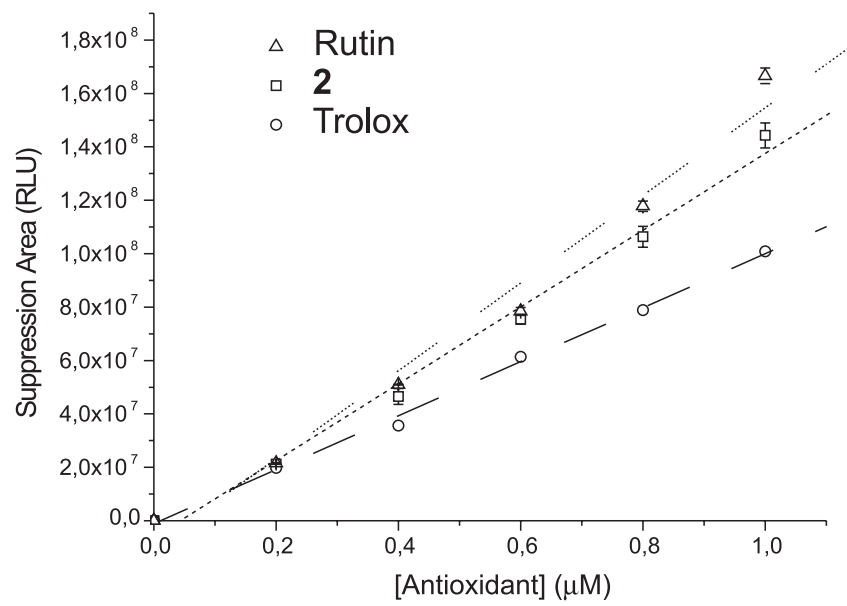

Figure 1. Correlation of the suppression area to antioxidant concentration. Concentrations: [luminol], $0.1 \mathrm{mM}$; [AAPH], $4 \mathrm{mM}$; Tris buffer (0.1 M), pH 9,0. The dashed lines correspond to the linear fitting. Trolo $x^{\oplus}: A=-0.0109 \pm$ $0.0445, B=(1.0108 \pm 0.0543) \times 10^{8}, R=0.9986, N=4$. Rutin: $A=-0.1996$ $\pm 0.093, B=(1.7840 \pm 0.1408) \times 10^{8}, R=0.9922, N=4.2: A=-0.1298 \pm$ $0.0182, B=(1.5297 \pm 0.0433) \times 10^{8}, R=0.9956, N=4$. At the 0.05 level, the means are significantly different
Table 2. Number of radicals trapped (n) by an inhibitor molecule

\begin{tabular}{lcc}
\hline Antioxidant & Number of OH groups & $n$ \\
\hline Trolox $^{\circledR}$ & 1 & $2^{\mathrm{a}}$ \\
Rutin & 4 & $3.53 \pm 0.07^{\mathrm{b}}$ \\
Derivative 2 & 4 & $3.03 \pm 0.08^{\mathrm{b}}$ \\
\hline
\end{tabular}

${ }^{\mathrm{a}}$ Data collected in ref $19 .{ }^{\mathrm{b}}$ Conditions: reaction mixture contained the free radical source [AAPH], $4 \mathrm{mM}$; [luminol], $100 \mu \mathrm{M}$; TRIS buffer, $0,1 \mathrm{M}, \mathrm{pH} 9.0$. Incubation of this mixture at $37^{\circ} \mathrm{C}$. This method was proposed in ref. 20 and 23

in a biological system in vitro. The free-radical chemistry of lipid peroxidation is a complex process whereby unsaturated lipid material undergoes a reaction with molecular oxygen to yield lipid hydroperoxides. In most situations that involve biological samples, the lipid hydroperoxides are broken down into a variety of products, including alkanals, alkenals, ketones and others, and to a low-molecular-weight product, specifically malondyaldehyde (MDA), that is widely studied. The inhibitory action of rutin and its derivative was determined using an autoxidizing system, specifically the rat brain homogenate, which contained a wide variety of transitional-metal complexes, organic acids and thiol compounds that created a more stable oxidant/antioxidant potential. ${ }^{33-37}$

The use of tissue homogenate offered several advantages: it was easier to obtain relatively large amounts of fresh material; for initial processing under simple standard conditions, no extraneous catalyst was required; the rate and pattern of spontaneous autoxidation was remarkably regular, precise and reproducible. ${ }^{27,33,38}$

A good parameter to compare the antioxidant activity of the various compounds was the concentration inhibiting $50 \%\left(\mathrm{IC}_{50}\right)$ of brain homogenate autoxidation, that is to say that lower $\mathrm{IC}_{50}$ values corresponded to higher antioxidant activities. The $\mathrm{IC}_{50}$ values were calculated by a statistical model, with a specific polynomial equation, of dose (concentration of antioxidants $(\mu \mathrm{M})$ ) as a function of effect (antioxidant activity (\%)). The dose dependence of the antioxidant activity of flavonols is shown in Figure 2. It is important to note that the best fitting curves using the polynomial model were used to obtain a residue that has the smallest possible magnitude.

The results shown in Figure 2 and Table 3 suggest that derivative 2's high water solubility $(\log P=-1.10 \pm 0.02)$ had no major impact on its antioxidant properties (as compared to those of less soluble rutin); indeed, there was only a small decrease of $19.38 \%$ in derivative 2's interaction rate with oxidized lipids of the brain homogenate membrane. Specifically, this value of the lipoperoxidation inhibition in rutin was $97.23 \%$ and in its derivative was $77.85 \%$, given proportion equality of flavonoid nucleus molar concentration. There were also slight differences between the $\mathrm{IC}_{50}$ of rutin $(12.46 \pm 0.18)$ and that of compound 2 (19.51 \pm 0.17$)$.

Table 3. Effects of rutin and its derivative $\mathbf{2}$ on lipid peroxidation in the brain homogenate

\begin{tabular}{lccc}
\hline & \multicolumn{3}{c}{ Brain } \\
\cline { 2 - 4 } Compounds & $\begin{array}{c}\text { MDA formation } \\
(535 \mathrm{~nm})\end{array}$ & Inhibition (\%) & $\mathrm{IC}_{50}$ \\
\hline Control (Buffer) & $0.542 \pm 0.056$ & & \\
Rutin * & $0.015 \pm 0.006$ & 97.23 & $12.46 \pm 0.18$ \\
$\mathbf{2} * *$ & $0.120 \pm 0.011$ & 77.85 & $19.51 \pm 0.17$ \\
\hline
\end{tabular}

The values are mean $\pm \mathrm{SD}(\mathrm{n}=3)$. All compounds were dissolved in ethanol $80 \%$ and tested at a final concentration of $*(67.12 \mu \mathrm{M})$ and $* *(33.84 \mu \mathrm{M})$. 


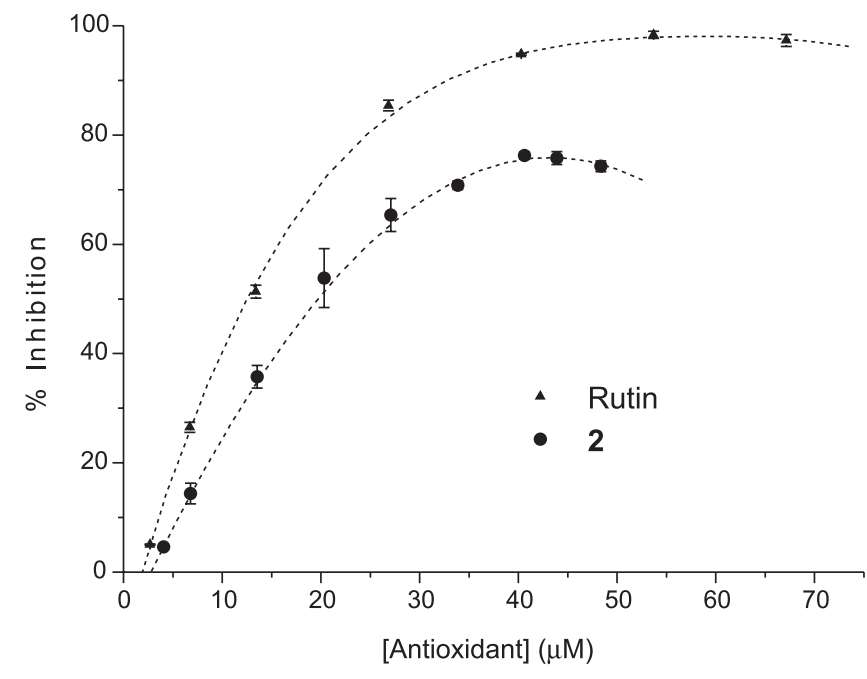

Figure 2. Correlation of lipid peroxidation inhibition to antioxidant concentration. Concentrations: dilute brain homogenate; [TCA], $(5 \%, w / v)$; [TBA], (0.67\%,w/v); phosphate buffer (40 mM) and $\mathrm{NaCl}(140 \mathrm{mM}), \mathrm{pH}$ 7.4. The absorbance of the MDA-TCA adduct was detected at $535 \mathrm{~nm}$. The dashed lines correspond to the polynomial fitting: $y=A+B 1 * x+B 2 * x^{\wedge} 2$ $+B 3 * x^{\wedge} 3+B 4^{*} x^{\wedge} 4$ (rutin) and $y=A+B 1 * x+B 2 * x^{\wedge} 2+B 3 * x^{\wedge} 3$ (succinyl rutin). Rutin: $A=-11.6131 \pm 0.6494, B 1=6.6046 \pm 0.3343, B 2=-0.1533$ $\pm 0.0228, B 3=(0.1640 \pm 5.0494) \times 10^{-4}, B 4=(-6.9279 \pm 3.5350) \times 10^{-6}, R$ $=0.99996, N=3.2: A=-10.7071 \pm 2.2369, B 1=3.9632 \pm 0.4444, B 2=$ $-0.0443 \pm 0.0200, B 3=(-0.2361 \pm 2.5363) \times 10^{-4}, R=0.99944, N=3 . A t$ the 0.05 level, the means are significantly different

\section{CONCLUSION}

Using a simple chemical modification, it was possible to synthesize a water-soluble derivative of rutin and to maintain the derivative's interaction ability with lipid-peroxidation products, such as malondyaldehyde, and also with water-soluble alkyl peroxyl radicals.

\section{ACKNOWLEDGMENTS}

We would like to thank Dr. L. H. Catalani for allowing use of the luminometer and Dr. A. Salatino for his assistance in the sample purification. Thank-you, also, to Dra. S. B. de M. Barros, Dr. D. A. Moraes and Dr. M. da S. Baptista for their assistance and helpful discussions. This work was supported by CAPES.

\section{ABBREVIATIONS USED}

ABAP, 2,2'-azobis-(2-amidinopropane) hydrochloride; AAPH, 2,2'-azobis-(2-amidinopropane) dihydro- chloride; RLU, relative light unit; TRAP, total radical-trapping antioxidant parameter; CL, chemiluminescence; ABTS, 2,2-azinobis-(3-ethylbenzothiazoline-6-sulfonic) acid; TBA, thiobarbituric acid; TCA, trichloroacetic acid; MDA, malondyaldehyde; luminol, 5-amino-2,3-dihydro-phthalazine-1,4-dione; Trolox ${ }^{\circledR}$ (water soluble homologue of vitamin E), 6-hydroxy-2,5,7,8-tetramethylchroman-2-carboxilic acid.

\section{REFERENCES}

1. Mccord, J. M.; Fridovich, I.; J. Biol. Chem. 1969, 224, 6049.

2. Sies, H.; Angew. Chem., Int. Ed. 1986, 25, 1058.

3. Aruoma, O. I.; Food Nutr. Chem. Toxic. 1994, 32, 671.

4. Briviba, K.; Sies, H. In Natural Antioxidants in Human Health and
Disease; Frei, B., ed.; Academic Press: California, 1994, ch. 2.

5. Halliwell, B.; Nutr. Rev. 1994, 52, 253.

6. Ferreira, A. L. A.; Matsubara, L. S.; Rev. Ass. Med. Brasil 1997, 43, 61.

7. Rusznyàk, S.; Szent-Gyorgyi, A.; Nature 1936, 138, 27.

8. Pathak, D.; Pathak, K.; Singla, A.K.; Fitoterapia 1991, 57, 371.

9. Middleton, E., Kandaswami, C.; Biochem. Pharmacol. 1992, 43, 1167.

10. Shahidi, F. In Natural Antioxidants - Chemistry, Health Effects and Applications; Shahidi, F., ed.; AOCS Press: USA, 1997, ch. 1.

11. Yao, L. H.; Jiang, Y. M.; Shi, J.; Tomás-Barberán, F. A.; Datta, N.; Singanusong, R.; Chen, S. S.; Plant. Foods Hum. Nutr. 2004, 59, 113.

12. Rice-Evans, C. A.; Miller, N. J.; Bolwell, G. P.; Bramley, P. M.; Pridham, J. B.; Free Radical Res. 1995, 22, 375.

13. Yildzoglu-Ari, N.; Altan, V. M.; Altinkurt, O.; Ozturk, Y.; Phytother. Res. 1991, 5, 19.

14. Duarte, J.; Perez-Vizcaino, F.; Zarzuelo, A.; Jimenez, J.; Tanargo, J.; Eur. J. Pharmacol. 1993, 239, 1.

15. Khalifa, T. I.; Muhtadi, F. J.; Hassan, M. M. A. In Analytical Profiles Drug Substances; Florey, K., ed.; Academic Press: New York, 1983, ch. 12.

16. Alluis, B.; Pérol, N.; El Hajjí, H.; Dangles, O.; Helv. Chim. Acta 2000, $83,428$.

17. Siegelman, H. W. J.; Biol. Chem. 1955, 213, 647.

18. Rothwell, J. A.; Day, A. J.; Morgan, M. R. A.; J. Agric. Food Chem. 2005, 53, 4355 .

19. Krasowska, A.; Rosiak, D.; Szkapiak, K.; Lukaszewicz, M.; Curr. Top. Biophys. 2000, 24, 89.

20. McLain, D. E.; Kalinich, J. F.; Ramakrishnan, N.; FASEB J. 1995, 9, 1345.

21. Saigo, M. G.; Bermúdez, E.; Squadrito, G.L.; Pryor, W. A.; Arch. Biochem. Biophys. 1995, 322, 500.

22. Saigo, M. G.; Pryor, W.A.; Arch. Biochem. Biophys, 1996, 333, 482.

23. Lissi, E.; Hanna-Salim, M.; Pascual, C.; Castillo, M. D.; J. Free Radicals Biol. Med. 1995, 18, 153.

24. Bastos, E. L.; Romoff, P.; Eckert, C. R.; Baader, W. J.; J. Agric. Food Chem. 2003, 51, 7481.

25. Lissi, E.; Pascual, C.; Castillo, M. D.; Free Radical Res. Commn. 1992, $17,299$.

26. Wayner, D. D. M.; Burton, G. W.; Ingold, K. U.; Locke, S.; FEBS J. 1985, 187, 33 .

27. Stocks, J.; Gutteridge, J. M. C.; Sharp, R. J.; Dormandy, T. L.; Clin. Sci. Mol. Med. 1974, 47, 212.

28. http://www.accessdata.fda.gov/scripts/cdrh/cfdocs/cfcfr/CFRSearch. cfm?fr=172.275, accessed in May 2005.

29. Sánchez-Moreno, C.; Food Sci. Technol. Int. 2002, 8, 121.

30. Lissi, E.A.; Aspée, A. J.; Protein Chem. 2001, 20, 479.

31. Jovanovic, S. V.; Steenken, S.; Tosic, M.; Marjanovic, B.; Simic, M. G.; J. Am. Chem. Soc. 1994, 116, 4846.

32. Heim, K.E.; Tagliaferro, A.R.; Bobilya, D.J; J. Nutr. Biochem. 2002, 13, 572.

33. Janero, D. R.; Free Radical Biol. Med. 1990, 9, 515.

34. Botsoglou, N. A.; Fletouris, D. J.; Papageorgiou, G. E.; Vassilopoulos, V. N.; Mantis, A. J.; Trakatellis, A. G.; J. Agric. Food Chem. 1994, 42, 1931.

35. Guillén-Sans, R.; Gusmán-Chozas, M.; Crit. Rev. Food Sci. Nutr. 1998, 38,315 .

36. Silva, F. A. M.; Borges, M. F. M.; Ferreira, M. A.; Quim. Nova 1999, 22, 94.

37. Porter, N.A.; Methods in Enzymology 1984, 105, 273.

38. Lissi, E.A.; Cárceres, T.; Videla, L. A.; J. Free Radicals Biol. Med. 1986, 2,63 . 